\title{
PENGEMBANGAN MEDIA PEMBELAJARAN BERBASIS MOBILE LEARNING PADA MATERI GELOMBANG BERJALAN DAN GELOMBANG STATIONER
}

\author{
Cika Kalista Adinda $^{\text {a) }}$, Siswoyo ${ }^{\text {b) }}$, Cecep E. Rustana ${ }^{\text {c) }}$ \\ Program Studi Pendidikan Fisika, FMIPA, Universitas Negeri Jakarta, Jakarta, 13220, Indonesia, Jl. \\ Rawamangun Muka, RT.11/RW.14, Rawamangun, Pulo Gadung, Kota Jakarta Timur, Daerah Khusus \\ Ibukota Jakarta 13220
}

Email: a)cikakalista@gmail.com,${ }^{\text {b) }}$ siswoyo@unj.ac.id,${ }^{\text {c) }}$ ce.rustana59@gmail.com

\begin{abstract}
Abstrak
Penelitian ini bertujuan untuk mengembangkan media pembelajaran berbasis mobile learning pada materi gelombang berjalan dan gelombang stasioner yang layak dalam pembelajaran di SMA. Metode penelitian yang digunakan adalah Research and Development dengan menggunakan model penelitian ADDIE. Langkah-langkah pengembangan ADDIE adalah analyze, design, develop, implementation dan evaluate. Media yang dihasilkan berupa aplikasi dapat digunakan pada perangkat Android dengan nama "Dynary Waves". Aplikasi ini terdiri dari 4 pilihan menu utama, yaitu kompetensi, peta konsep, materi, dan kuis. Pada aplikasi ini dilengkapi juga dengan GAMBAR, grafik, animasi, simulasi dan video. Hasil validasi produk oleh ahli materi memiliki persentase $87.11 \%$, ahli media $76.25 \%$, serta hasil uji coba produk oleh guru fisika SMA sebesar $91.91 \%$ dan oleh siswa sebesar $85.40 \%$ yang termasuk dalam interpretasi layak. Sehingga aplikasi Dynary Waves pada materi gelombang berjalan dan gelombang stasioner layak dalam pembelajaran fisika di SMA.
\end{abstract}

Kata-kata kunci: $R \& D$, Mobile Learning, Dynamic Wave and Stasionary Wave

\begin{abstract}
The purposed of this research is to developing a worthy instructional media based on mobile learning in dynamic wave and stationary wave for high school students. The research method used is research and development with ADDIE models. The developing steps of ADDIE's are analyze, design, develop, implementation, and evaluate. The product is an application that can be downloaded free on android phone titled "Dynary Waves". This application contains 4 main menus, are competition, concept map, content, and quiz. In this app contains of picture, graphic, animation, simulation, and video. The results of product validated by subject content experts has a percentage of $87,11 \%$, media experts $76.25 \%$, and the results of product trials by high school physics teachers are $91.91 \%$ and by students $85.40 \%$ which are included in the worth interpretation. So that the Dynary Waves application in content of travelling and stationary deserves to be used in high school.
\end{abstract}

Keywords: $R \& D$, Mobile Learning, Dynamic Wave and Stasionary Wave 


\section{PENDAHULUAN}

Abad 21 merupakan abad pengetahuan, abad di mana informasi banyak tersebar dan teknologi berkembang. Karakteristik abad 21 ditandai dengan semakin bertautnya dunia ilmu pengetahuan, sehingga sinergi diantaranya menjadi semakin cepat. Dalam konteks pemanfaatan teknologi informasi dan komunikasi di dunia pendidikan, telah terbukti dengan semakin menyempit dan meleburnya faktor "ruang dan waktu" yang selama ini menjadi aspek penentu kecepatan dan keberhasilan ilmu pengetahuan oleh umat manusia [1]. Abad 21 juga ditandai dengan banyaknya (1) informasi yang tersedia di mana saja dan dapat diakses kapan saja; (2) komputasi yang semakin cepat; (3) otomasi yang menggantikan pekerjaan-pekerjaan rutin; dan (4) komunikasi yang dapat dilakukan dari mana saja dan kemana saja [2].

Perkembangan teknologi mobile saat ini begitu pesat, salah satu perangkat mobile yang saat ini sudah umum digunakan adalah telepon seluler. Hampir $90 \%$ siswa pasti sudah mempunyai satu telepon seluler atau bahkan ada yang mempunyai lebih dari satu telepon seluler. Semakin banyaknya siswa yang memiliki dan menggunakan perangkat mobile maka semakin besar pula peluang penggunaan perangkat teknologi dalam dunia pendidikan. Media pembelajaran yang memanfaatkan teknologi telepon seluler disebut dengan mobile learning (M-Learning). Mobile learning merupakan salah satu alternatif pengembangan media pembelajaran. Kehadiran mobile learning ditujukan sebagai pelengkap pembelajaran serta memberikan kesempatan pada siswa untuk mempelajari materi yang kurang dikuasai di manapun dan kapanpun [3].

Guru profesional dituntut mampu memilih dan menggunakan berbagai jenis media pembelajaran yang ada di sekitarnya. Demikian juga dalam pembelajaran Fisika, guru Fisika harus mampu menggunakan media pembelajaran dalam proses pembelajaran. Fisika merupakan salah satu mata pelajaran dalam disiplin Ilmu Pengetahuan Alam yang masih dianggap sulit oleh siswa. Hasil survey pada penelitian menunjukkan bahwa rata-rata siswa tidak tertarik untuk mempelajari Fisika, hal ini dikarenakan Fisika merupakan mata pelajaran yang sulit untuk dipelajari. Anggapan tersebut secara tidak langsung membentuk pemahaman di dalam pemikiran siswa, sehingga siswa merasa tidak mampu sebelum mempelajari dan membuat siswa lebih memilih hafalan rumus daripada mengutamakan pemahamanya [4].

Materi Fisika yang bersifat abstrak inilah yang membuat siswa harus memahami konsep daripada sekedar menghafalkan rumus. Dalam mempelajari Fisika diperlukan pendekatan yang tepat agar paradigma siswa terhadap mata pelajaran Fisika berubah menjadi lebih baik. Dengan berubahnya paradigma siswa terhadap pembelajaran Fisika akan memberikan dampak positif terhadap hasil belajar siswa di kelas. Guru diharapkan dapat membuat siswa berperan aktif untuk mengembangkan dirinya dalam kegiatan pembelajaran. Hal ini dikarenakan kegiatan pembelajaran merupakan suatu proses usaha yang dilakukan individu untuk memperoleh perubahan tingkah laku yang baru secara keseluruhan sebagai hasil pengalaman individu dalam berinteraksi dengan lingkungan [5].

Guru sebagai pengelola pembelajaran harus mengubah mindset yaitu dari yang semula berpusat pada guru menjadi pembelajaran inovatif yang berpusat pada siswa, karena guru tidak akan mampu lagi sebagai sumber informasi utama bagi siswanya, tetapi lebih berperan sebagai fasilitator dan inspirator yang bertugas mengarahkan dan menstimulli siswa sehingga siswa menemukan dan membangun pengetahuannya sendiri dari berbagai sumber belajar dan kemudian menggunakan pengetahuannya untuk memecahkan permasalahan dalam kehidupan nyata [6].

Sebanyak $28,89 \%$ siswa merasa materi gelombang berjalan dan gelombang stasioner sebagai materi yang sulit untuk dipelajari, 26,67\% siswa merasa materi thermodinamika sebagai materi yang sulit untuk dipelajari, 21,11\% siswa merasa materi gelombang mekanik sulit untuk dipelajari, 16,67\% siswa merasa materi gelombang bunyi dan cahaya sulit untuk dipelajari dan tidak semua siswa tidak menjadi permasalahan dalam pembelajaran Fisika untuk dipelajari dengan persentase kesulitan 0\% [7].

Adapun analisis kebutuhan yang dilakukan di SMAN 21 Jakarta, yang menggunakan 15 siswa dari kelas 12 dan 15 siswa dari kelas 11 sebagai responden. Analisis tersebut mendapat hasil bahwa sekitar 76,7\% siswa menganggap bahwa gelombang berjalan dan gelombang stasioner merupakan 
materi yang sulit dipahami. Karena, $80 \%$ guru masih menggunakan metode ceramah pada materi ini. Sebanyak $96,7 \%$ siswa membutuhkan media pembelajaran yang menarik dan kreatif.

Adapun analisis kebutuhan yang dilakukan di SMAN 21 Jakarta yang menggunakan 3 guru fisika sebagai responden. Semua guru fisika menganggap materi gelombang berjalan dan gelombang stasioner merupakan materi yang sulit dipahami siswa karena waktu yang kurang dan materinya abstrak. Hanya 1 dari 3 guru yang memakai media pembelajaran berupa video interaktif dan eksperimen, 2 dari 3 guru menggunakan metode ceramah, dan 3 dari 3 guru menggunakan metode diskusi. Kurangnya pengetahuan akan teknologi pada guru menjadikan terbatasnya media pembelajaran yang dapat dimanfaatkan. Karena hanya 1 dari 3 guru yang pernah menggunakan media pembelajaran berbasis mobile.

Adolphus \& Aderonmu mengidentifikasi terdapat dua kemungkinan, yang pertama karena kemampuan siswa dalam memecahkan masalah yang bersifat matematis memang sangat lemah dan yang kedua karena siswa tidak tahu bagaimana menerapkan persamaan matematis pada permasalahan Fisika dalam kehidupan sehari-hari. Hal ini menunjukkan bahting bagi siswa untuk meningkatkan penguasaan konsep dalam mempelajari konsep-konsep Fisika [8].

Berdasarkan informasi data dan studi pendahuluan yang telah dilakukan, maka menjadi dasar untuk melakukan penelitian pengembangan mengenai "Pengembangan media pembelajaran berbasis mobile learning pada materi gelombang berjalan dan gelombang stasioner".

\section{METODOLOGI}

Metode penelitian yang digunakan adalah metode penelitian dan pengembangan (Research and Development). Menurut Sugiyono, penelitian dan pengembangan memiliki tujuan untuk menghasilkan produk baru melalui proses pengembangan [9]. Model penelitian dan pengembangan yang digunakan dalam penelitian pengembangan bidang pendidikan adalah model ADDIE. Langkahlangkah pengembangan ADDIE adalah analyze, design, develop, implement dan evaluate [10]. Pengembangan m-learning ini menggunakan model penelitian dan pengembangan ADDIE yang dijelaskan dalam tahapan-tahapan berikut ini:

\section{1) Analyze}

Pada tahap ini peneliti menganalisis kebutuhan subjek penilitian, yaitu para siswa SMAN. Siswa SMAN yang diambil sebagai sampel untuk analisis ialah siswa SMAN 21 Jakarta. Setelah dilakukan analisis kebutuhan, data kemudian diolah dan mendapat hasil yang menyatakan bahwa siswa SMAN menganggap bahwa materi gelombang berjalan dan gelombang stasioner merupakan materi yang sulit dan abstrak untuk dipelajari dan membutuhkan media pembelajaran yang memudahkan siswa. Pada tahapan ini juga dilakukan studi literatur sekaligus komparasi dengan penelitian sebelumnya baik mengenai mobile learning [11-12], pembelajaran pada perangkat android [13-14], maupun konten materi terkait [15-18].

\section{2) Design}

Pada langkah ini dilakukan perancangan aplikasi android yang sesuai dengan data analisis kebutuhan yang didapatkan, pada perancangan ini sesuai dengam KD 3.9 yaitu menganalisis besaran-besaran fisis gelombang stasioner dan gelombang berjalan pada berbagai kasus nyata.

\section{3) Development}

Peneliti melakukan tahap pengembangan aplikasi dengan membuat aplikasi android materi gelombang berjalan dan gelombang stasioner menggunakan Adobe Flash Professional CS6. Sebelum masuk ke tahap berikutnya yaitu implementasi, dilakukan terlebih dahulu uji validasi. Jika diterima akan dilanjutkan ke tahapan revisi (evaluation), lalu ke implementasi akhir yaitu uji lapangan.

\section{4) Implementation}

Pada implementasi dilakukan uji lapangan, yaitu pengujian produk akhir berupa aplikasi kepada siswa SMAN 21 Jakarta yang dijadikan sebagai sampel subjek.

\section{5) Evaluation}


Tahapan evaluasi terdapat disetiap langkah ADDI, pada tahap analisis dilakukan evaluasi berupa hasil analisis kebutuhan. Pada tahap desain dilakukan evaluasi berupa revisi desain dari dosen pembimbing. Pada tahap pengembangan dilakukan evaluasi berupa revisi dari para validator baik ahli materi ataupun ahli media. Dan pada tahap implementasi dilakukan evaluasi hasil responden.

\section{HASIL DAN PEMBAHASAN}

Hasil dari pengembangan ini berupa aplikasi android pada pokok bahasan gelombang berjalan dan gelombang stasioner. Produk yang dikembangkan berupa media pembelajaran berbasis mobile learning berbasis android. Spesifikasi tampilan landscape berukuran 1270 x 720 pixel yang seukuran dengan telepon genggam android pada umumnya. Jenis huruf untuk judul menu adalah Bauhaus 93, untuk isi menggunakan Geometr415 Blk BT. Ukuran huruf untuk judul menu 70 pt, sedangkan untuk isi 30 pt.

Aplikasi dibuat menggunakan Adobe Flash Professional CS6. Desain background dibuat menggunakan Canva. Ikon/tombol dibuat menggunakan CorelDraw X7. Video latihan soal dibuat menggunakan VideoScribe Pro dan diperbaiki menggunakan VSDC Video Editor.

Pada setiap awal sub-bab, terdapat tampilan Tahukah Kamu yang berisi GAMBAR atau video sebagai stimulus agar siswa dapat mengetahui pembelajaran apa yang akan didapat. Setelah mengamati GAMBAR atau video, diharapkan siswa dapat menjawab pertanyaan yang ada di bawahnya. Lalu pada tampilan berikutnya terdapat jawaban untuk menyamakan persepsi antara jawaban siswa dan konsep.

Setelah itu siswa diajak untuk mencoba simulasi PhET, yang telah terkoneksi. Siswa diminta mencatat data yang tersedia jika pilihannya berbeda. Hal ini dilakukan agar siswa dapat bertanya dan mengumpulkan data. Pada tahap ini adalah tahap menanya dan mengumpulkan data.

Setelah itu dijelaskan secara terperinci tentang materi masing-masing sub-bab, lengkap dengan video animasi tentang materi dan video contoh soal. Tahap ini juga bisa menjadi tahap mengumpulkan data dan mengasosiasi.

Setelah semua materi dibahas, maka akan ada kesimpulan pada akhir sub-bab. Pada tahap ini termasuk tahap menyimpulkan, maka pembelajaran model 5M telah selesai.

Pada setiap tampilan layar terdapat tombol Beranda untuk kembali ke halaman beranda dan tombol Keluar untuk keluar dari aplikasi. Pada tombol Keluar akan muncul tampilan untuk meyakinkan siswa untuk keluar aplikasi atau tidak. Jika siswa menekan ya, maka aplikasi otomatis akan keluar. Dan jika siswa menekan tidak, maka aplikasi otomatis akan kembali pada menu beranda.

Pada layar isi sub-bab materi terdapat tombol Kembali dan Selanjutnya, yang berfungsi untuk kembali atau lanjut ke tampilan berikutnya.

Produk penelitian aplikasi ini divalidasi dari 2 aspek yaitu aspek media dan materi. Hasil validasi akan digunakan untuk keperluan revisi dan bertujuan untuk mengetahui kelayakan dari produk yang dikembangkan sebelum diujicoba terhadap peserta didik. Berikut adalah tampilan-tampilan pada media pembelajaran yang dikembangkan :

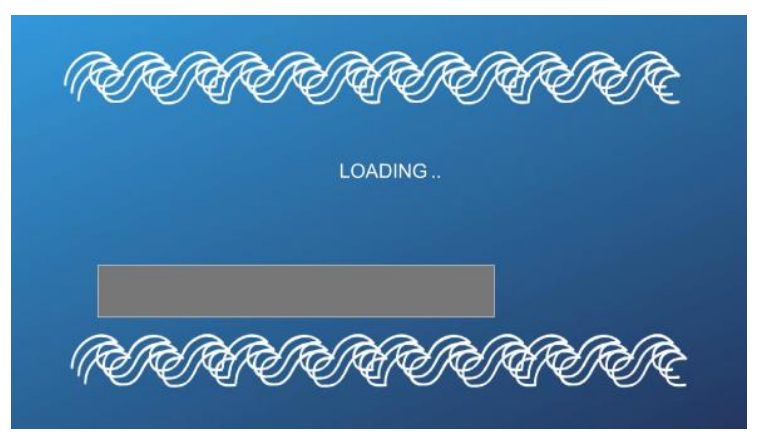

GAMBAR 1. Tampilan Slash Screen

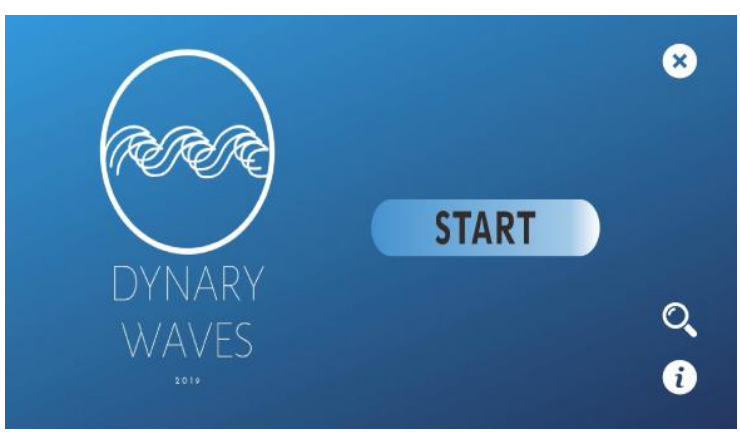

GAMBAR 2. Tampilan Awal 


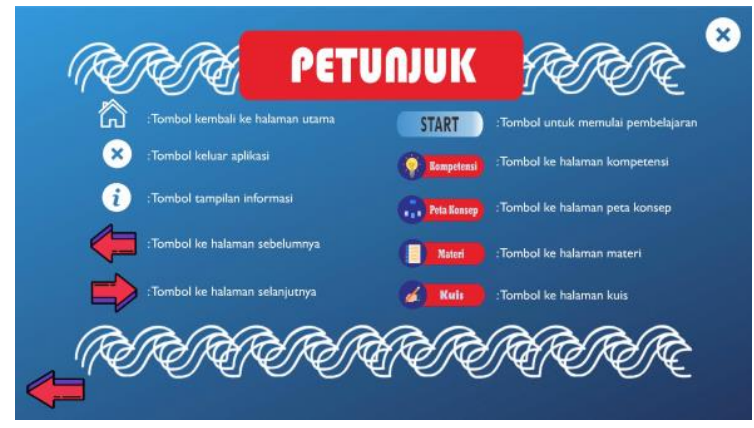

GAMBAR 3. Tampilan Petunjuk

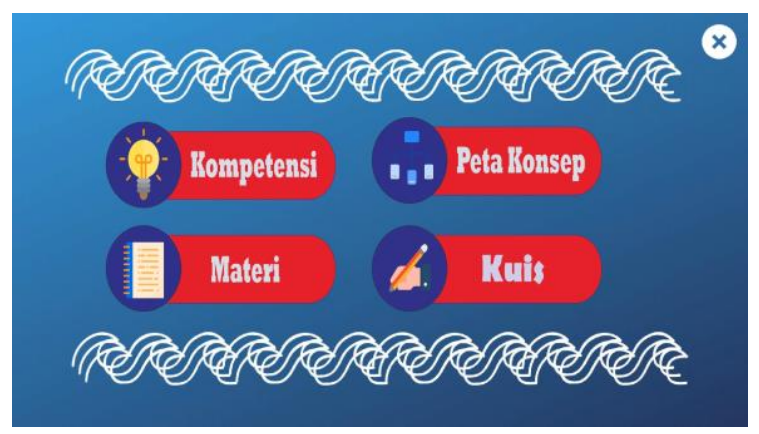

GAMBAR 5. Tampilan Beranda

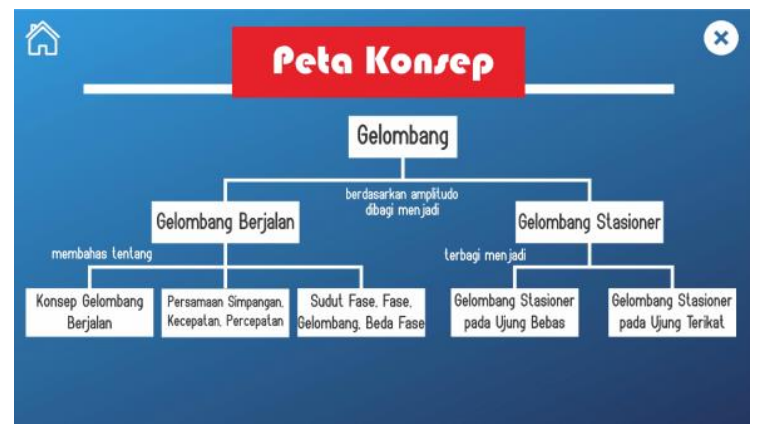

GAMBAR 7. Tampilan Peta Konsep

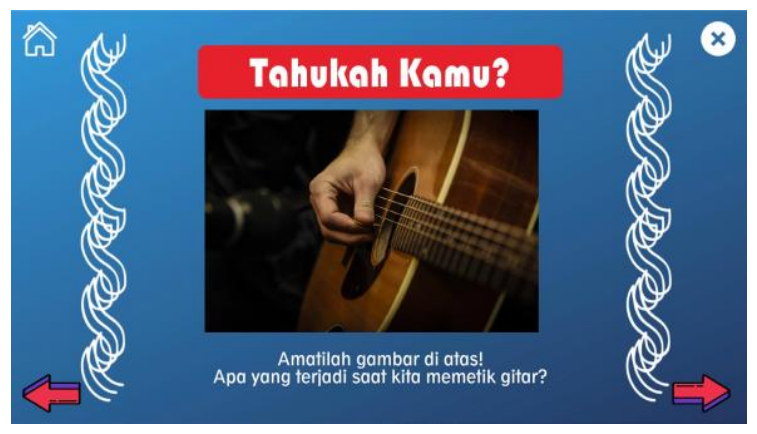

GAMBAR 9. Tampilan Awal Sub-Bab

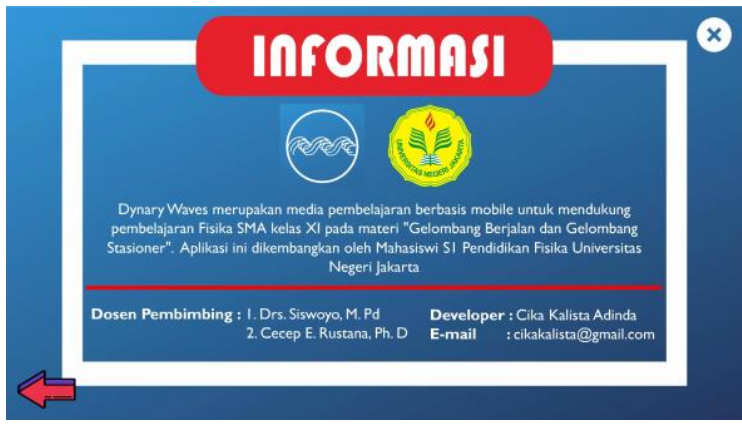

GAMBAR 4. Tampilan Informasi

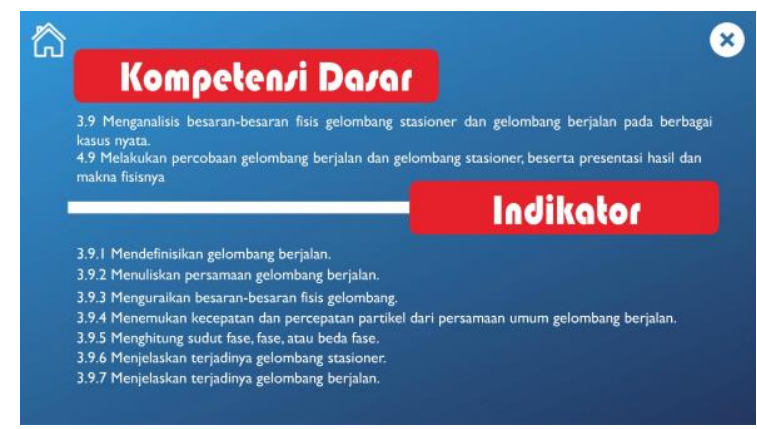

GAMBAR 6. Tampilan Kompetensi

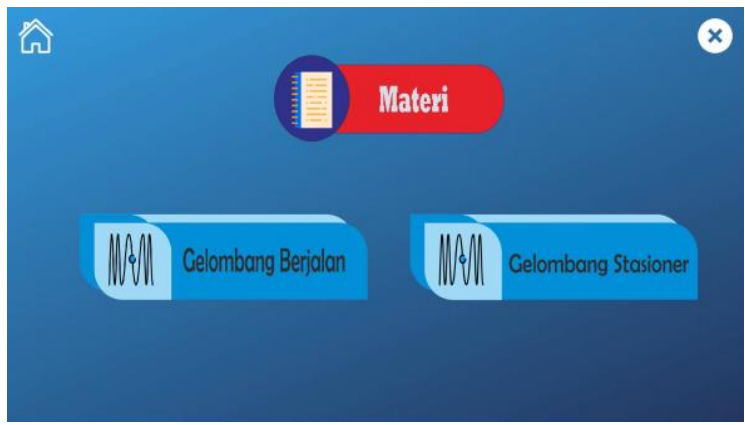

GAMBAR 8. Tampilan Pilihan Materi

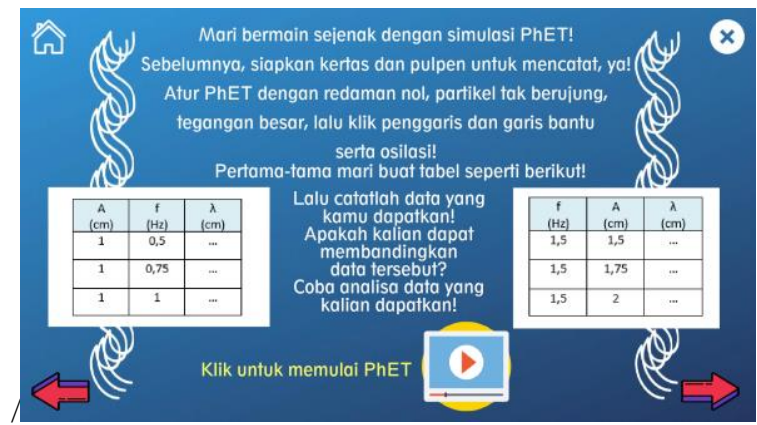

GAMBAR 10. Tampilan dengan PheT 


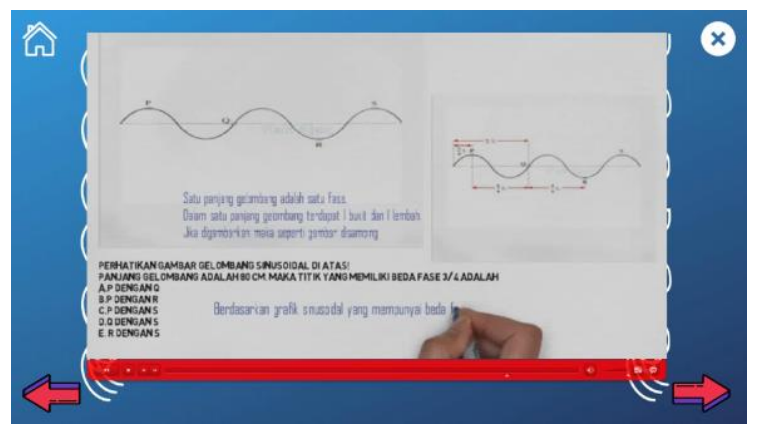

GAMBAR 11. Tampilan Video Pembahasan Soal

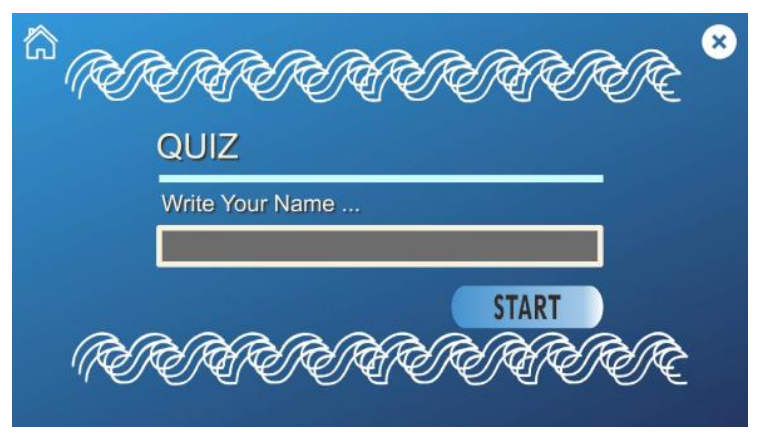

GAMBAR 13. Tampilan Awal Kuis

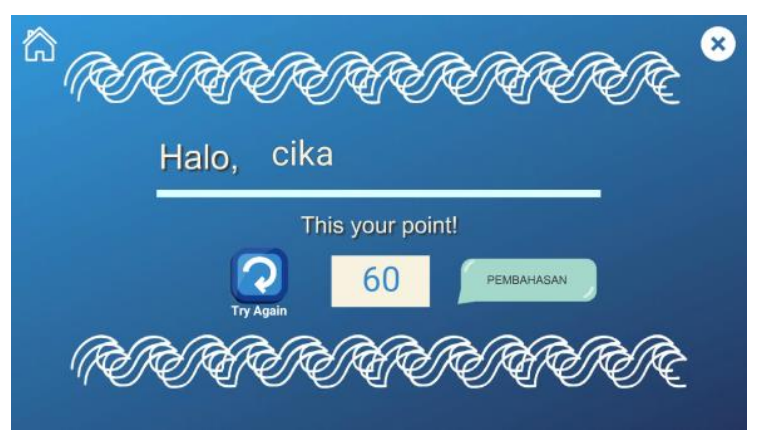

GAMBAR 15. Tampilan Hasil

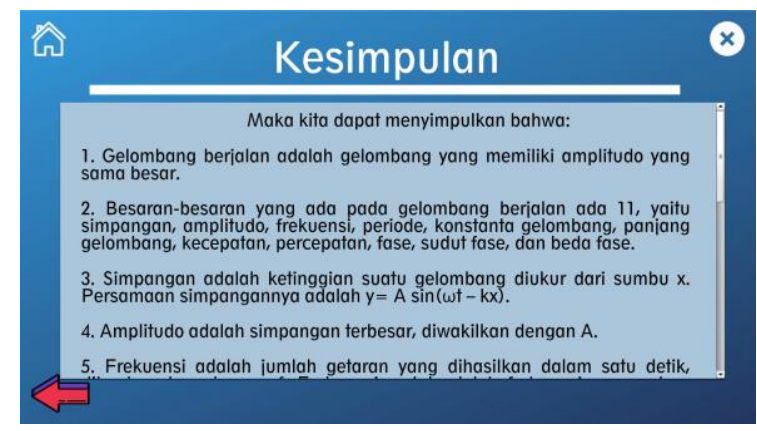

GAMBAR 12. Tampilan Kesimpulan

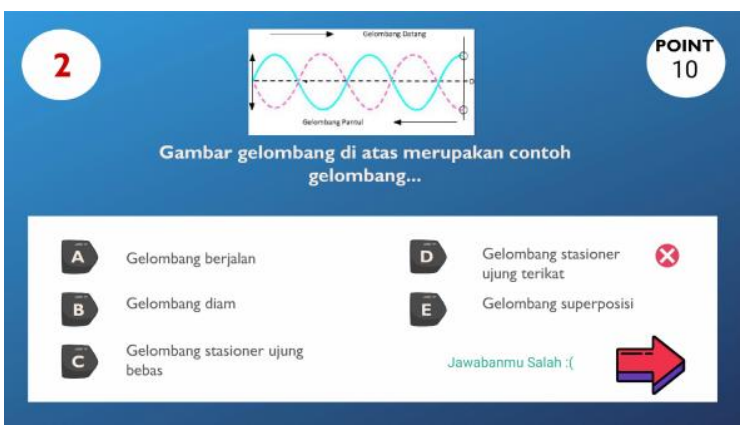

GAMBAR 14. Tampilan Soal

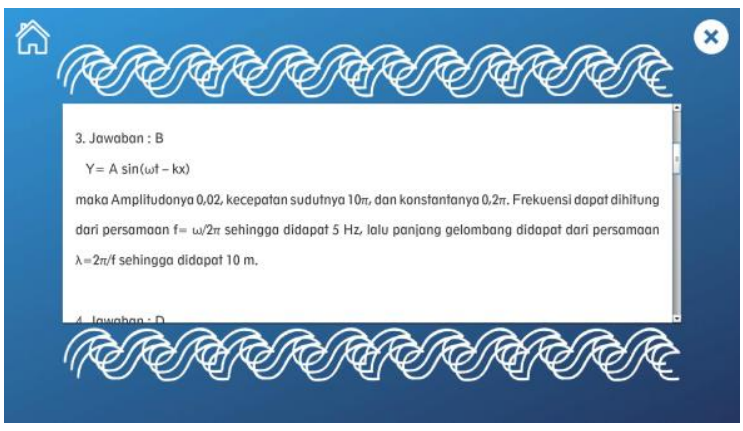

GAMBAR 16. Tampilan Pembahasan

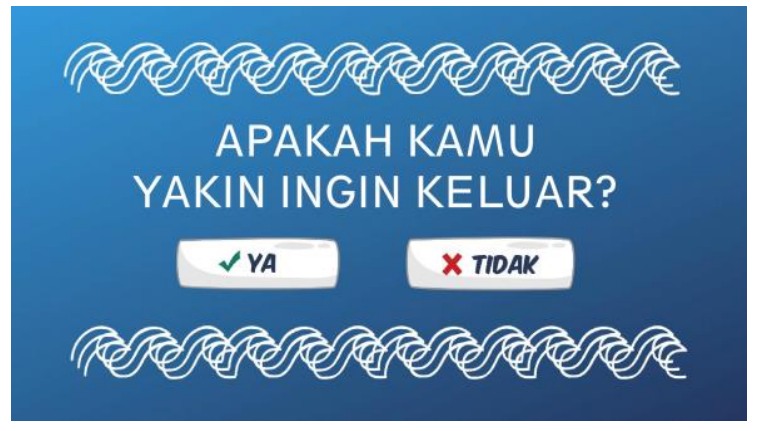

GAMBAR 17. Tampilan Keluar

Produk yang sudah menjadi media pembelajaran setelah itu diuji kelayakannya oleh ahli materi dan ahli media. Hasil uji kelayakan tersebut seperti di bawah ini 


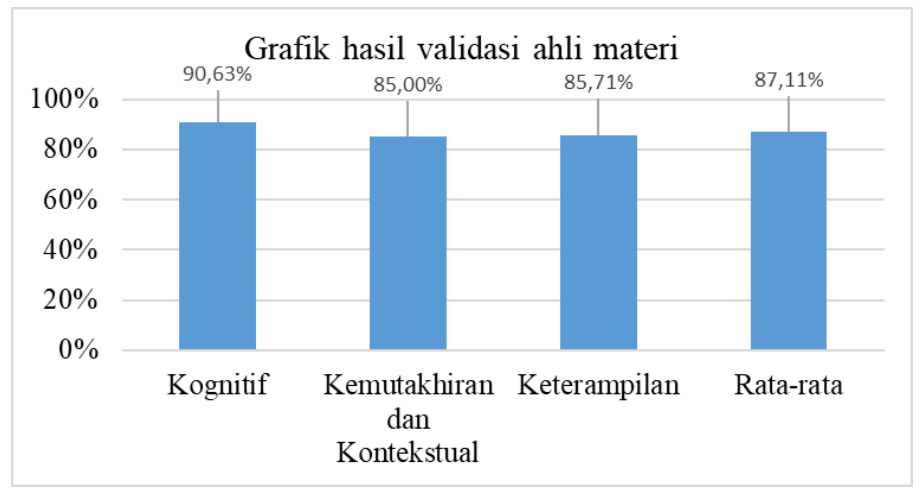

GAMBAR 18. Hasil validasi oleh ahli materi

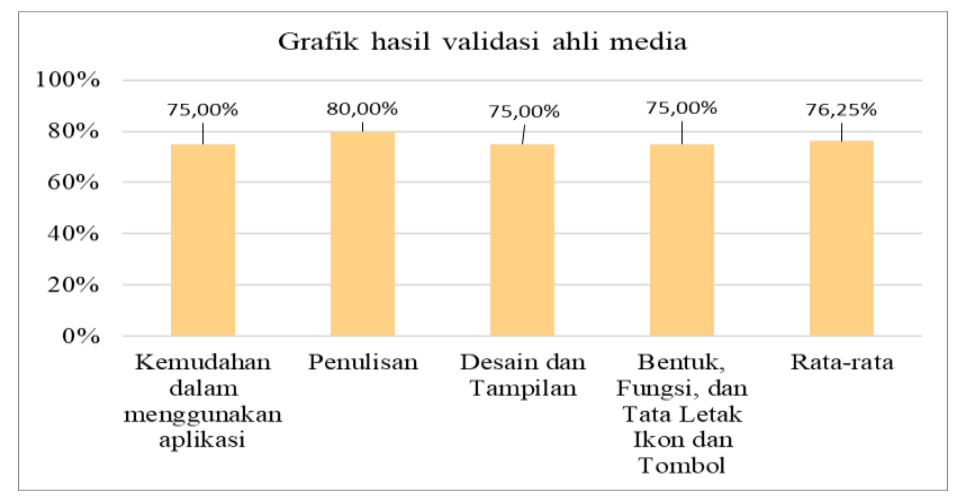

GAMBAR 19. Hasil validasi oleh ahli media

Dari grafik validasi oleh ahli materi diatas dapat diperoleh rata-rata $87,11 \%$ dan dapat diinterpretasikan layak dengan beberapa revisi yang diajukan. Selanjutnya dari grafik validasi oleh ahli media diperoleh rata-rata sebesar $76,25 \%$ yang dapat diinterpretasikan layak dengan beberapa revisi.

Setelah melakukan revisi yang diajukan oleh vallidator, maka tahap selanjutnya melakukan uji coba responden. Diperoleh 30 responden siswa SMAN 21 Jakarta dan 3 orang guru fisika SMAN 21 Jakarta sebagai berikut.

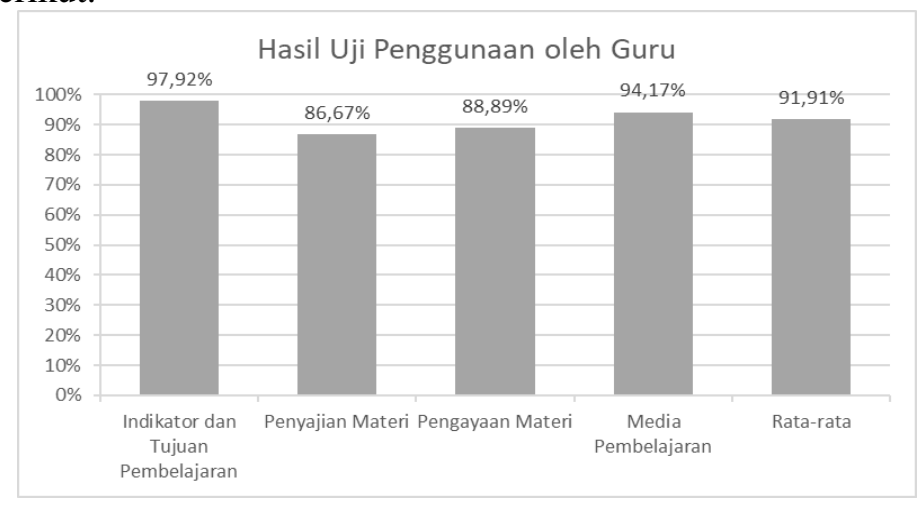

GAMBAR 20. Hasil Responden Guru 


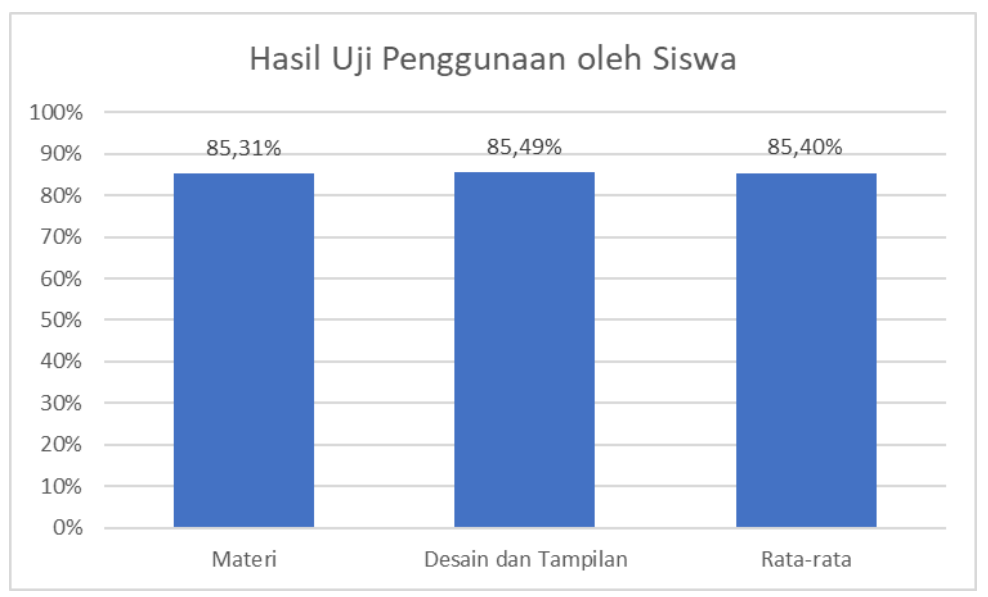

GAMBAR 21. Hasil Responden Siswa

\section{SIMPULAN}

Berdasarkan hasil uji kelayakan oleh ahli materi dan ahli media, kemudian di uji coba penggunaan oleh guru dan siswa SMA Kelas XII SMAN 21 Jakarta, dapat disimpulkan bahwa media pembelajaran berbasis mobile learning pada materi gelombang berjalan dan gelombang stasioner dinyatakan layak sebagai salah satu media pembelajaran fisika di SMA.

\section{REFERENSI}

[1] BSNP. (2006). Standar Isi Untuk Satuan Pendidikan Dasar dan Menengah. Jakarta.

[2] Kemendikbud. (2014). Permendikbud No. 61 Tentang Kurikulum Tingkat Satuan Pendidikan. Jakarta: Kementrian Pendidikan dan Kebudayaan.

[3] Wirawan, P. W. (2011). Pengembangan Kemampuan E-Learning berbasis Web ke dalam MLearning. Jurnal Universitas Diponegoro (Vol. 2 No. 4), 22-23.

[4] Soong, M. B. (2009). Students' Difficulties When Solving Physics Problems: Results from an ICT-infused Revision Intervension. Proceedings of the 17th International Conference on Computer in Education, 361-365.

[5] Ahdinirwanto, W., Lestari, R., \& Ashari. (2013). Peningkatan Pemecahan Masalah Melalui Model Pembelajaran Cooperative Integrated Reading and Composition (CIRC) pada SMP Negeri 4 Wadaslintang. Jurnal Radiasi, 178-181.

[6] Wasis. (2015). Hasil Pembelajaran Sains di Indonesia. Prosiding Seminar Nasional Pendidikan Sains PPs Pendidikan Sains UNESA.

[7] Istyowati, A. (2017). Analisis Pembelajaran Dan Kesulitan Siswa Sma Kelas Xi Terhadap Penguasaan Konsep Fisika. Jurnal Prosiding Seminar Nasional III Universitas Negeri Malang.

[8] Adolphus, T., \& Aderonmu, B. S. (2008). Factors Affecting The Teaching and Learning of Electromagnetism Among Secondary School Physics Students. Nigeria Journal of Vocational Teacher Education, 25-37.

[9] Sugiyono. (2013). Metode Penelitian dan Pengembangan Research and Development. Bandung: Alfabeta.

[10] Suparman, M. A. (2014). Desain Instruksional Modern. Jakarta: Erlangga. 
[11] I. A. D. Astuti, R. A. Sumarni, and D. L. Saraswati, "Pengembangan Media Pembelajaran Fisika Mobile Learning berbasis Android", jpppf, vol. 3, no. 1, pp. 57 - 62, Jun. 2017.

[12] B. R. Simanjuntak, D. Desnita, and E. Budi, "The Development of Web-based Instructional Media for Teaching Wave Physics on Android Mobile", jpppf, vol. 4, no. 1, pp. 1 - 10, Jun. 2018.

[13] I. A. D. Astuti, R. A. Sumarni, and D. L. Saraswati, "Pengembangan Media Pembelajaran Fisika Mobile Learning berbasis Android”, jpppf, vol. 3, no. 1, pp. 57 - 62, Jun. 2017.

[14] Muliyati, D., Bakri, F., \& Ambarwulan, D, "Aplikasi Android Modul Digital Fisika Berbasis Discovery Learning. WaPFi (Wahana Pendidikan Fisika)", 3(1), 74-79, 2018.

[15] E. Budi, "Kajian Fisis pada Gerak Osilasi Harmonis", jpppf, vol. 1, no. 2, pp. 59 - 66, Dec. 2015.

[16] H. Kurniawati, D. Desnita, and S. Siswoyo, "Pengembangan Media Pembelajaran Berbasis 3D PageFlip Fisika untuk Materi Getaran dan Gelombang Bunyi”, jpppf, vol. 2, no. 1, pp. 97 102, Jun. 2016.

[17] S. R. Hidayat, "Pengembangan Instrumen Tes Keterampilan Pemecahan Masalah pada Materi Getaran, Gelombang, dan Bunyi”, jpppf, vol. 3, no. 2, pp. 157 -166, Dec. 2017.

[18] Bakri, Fauzi, Diah Ambarwulan, and Dewi Muliyati. "Pengembangan Buku Pembelajaran Yang Dilengkapi Augmented Reality Pada Pokok Bahasan Gelombang Bunyi Dan Optik." Gravity: Jurnal Ilmiah Penelitian dan Pembelajaran Fisika, vol. 4, no.2, 2018. 
